\title{
Selection of Monokaryotic Isolates of Pleurotus sajor-caju, Pleurotus flabellatus and Pleurotus djamor for their Dikaryotization
}

\author{
Aparajita Dhar $^{1}$, K. Sinijadas ${ }^{2}$, Pulak Bhaumik ${ }^{1}$, \\ Suman Datta ${ }^{3}$ and Sekhar Bandyopadhyay ${ }^{1} *$ \\ ${ }^{1}$ Department of Plant Pathology, Uttar Banga Krishi Viswavidyalaya, \\ Pundibari, Coochbehar - 736165, West Bengal, India \\ ${ }^{2}$ Department of Plant Pathology, College of Agriculture, Kerala Agricultural University, \\ Vellayani, Thiruvananthapuram, Kerala - 695522, India \\ ${ }^{3}$ Department of Plant Pathology, Bidhan Chandra Krishi Viswavidyalaya, Mohanpur, \\ Nadia - 741252, West Bengal, India \\ *Corresponding author
}

\section{A B S T R A C T}

\section{Keywords}

Pleurotus

flabellatus,

Pleurotus sajor-

caju, Pleurotus

djamor,

Monokaryotic,

Dikaryotization,

Malt extract agar

Article Info

Accepted:

14 November 2020

Available Online:

10 December 2020
The experiment was conducted at UBKV, Pundibari, Coochbehar during the academic year of 2016 - 2018 to find out the monokaryotic isolates of P. flabellatus, $P$. sajor-caju and $P$. djamor (oyster pink or OP) for its dikaryotization with the help of rapidity in the growth performance. Eighteen, six and five monokaryotic isolates of P. flabellatus (PFM), $P$. sajor-caju (PSCM) and $P$. djamor (OPM), respectively were grown on Malt Extract Agar media (MEA) for testing their rapidity in radial growth. After the selection of monokaryotic isolates growth performance was again tested for selection of dikaryotic culture on Malt Extract Agar (MEA) media. In MEA media, rapid radial growth of monokaryotic isolates viz., PF8M, PF11M, PF16M and PF17M for P. flabellatus, PSC3M and PSC5M for P. sajor-caju, OP1M and OP5M for P. djamor (oyster pink or OP) was finally selected for dikaryotization (hybridization). Highest growth rate on MEA was observed in interspecific hybrids of PF $\times$ PSC12 $(18.50 \mathrm{~mm} /$ day $)$, PF $\times$ PSC16 $(18$ $\mathrm{mm} /$ day $), \mathrm{PF} \times \mathrm{PSC} 17$ (17.50 mm/day), PF $\times$ PSC8 $(17 \mathrm{~mm} /$ day $)$ and PF $\times$ PSC2 (16.50 $\mathrm{mm} /$ day $)$, respectively. Interspecific hybrids of OP $\times$ PSC5 $(21.50 \mathrm{~mm} /$ day $)$ followed by OP $\times$ PSC4 $(21 \mathrm{~mm} /$ day $)$, OP $\times$ PSC8 (20.50 mm/day) and OP $\times$ PSC12 (19.50 mm/day) and hybrids of $\mathrm{OP} \times \mathrm{PF} 5, \mathrm{OP} \times \mathrm{PF} 1, \mathrm{OP} \times \mathrm{PF} 2, \mathrm{OP} \times \mathrm{PF} 4$ shows the growth rate above $18 \mathrm{~mm} /$ day. Dikaryotic mycelium showed highest growth rate as compared to monokaryotic isolates of $P$. flabellatus, $P$. sajor-caju and $P$. djamor (oyster pink).

\section{Introduction}

Pleurotus spp. known as oyster mushroom is widely appreciated for its unique flavour, texture, colour, high shelf life and poor substrate specificity. Undoubtedly mushrooms were one of man's earliest foods which belong to the Kingdom Fungi due to unique fungal characteristics which draw a clear line from animals and plants. Unlike 
green plants, mushrooms are heterotrophs. Mushroom is a saprophytic fungus that grows on dead and decaying organic matter. Due to the absence of chlorophyll, it is unable to synthesize its own food and hence is dependent upon the organic matter/substrate for food. They were often considered as an exotic and luxurious food reserve for the rich. Today mushroom is food for both the rich and the poor. Now-a-days for strain improvement in mushrooms, several modified breeding techniques such as selection and hybridization by the process of protoplast fusion, use of chemical mutagenesis, use of resistance markers, have been employed with new findings of high yielding, more nutritious, disease resistance and more biological efficiency. Besides these, dikaryotization of selective strains is another very important tool in strain improvement for bringing genetic recombination and developing somatic hybrids. It can be grown anywhere as long as the conditions for its growth and cultivation are provided. Oyster mushrooms (Pleurotus spp.) are most suited in country like India which is rich in agricultural wastes as straw, saw dust; sugarcane bagasse and others are easily available here. Since, pollution by crop residue fire smoke in the month of February March is a major problem in India now-adays, cultivation of mushroom is a very promising alternative to utilize the agricultural waste into a valuable product.

\section{Materials and Methods}

\section{Place of experimentation}

The laboratory experiments were done in Research Laboratory, Department of Plant Pathology, Uttar Banga Krishi Viswavidyalaya, Pundibari, Coochbehar.

\section{Media}

The Culture media were sterilized in an autoclave at $121{ }^{\circ} \mathrm{C}$ for 15 minutes at 15 p.s.i.
In this course of investigation, two media i.e. Potato Dextrose Agar (PDA) and Malt Extract Agar (MEA) were used.

\section{Mushroom species used and their maintenance}

Fruit bodies from three Pleurotus species namely $P$. flabellatus, $P$. sajor-caju and $P$. djamor (oyster pink) were collected from KVK farm of Uttar Banga Krishi Viswavidyalaya. Pure cultures were made from these fruit bodies by tissue culture technique. From the tip of the hyphal growth mycelial segment was taken and transferred to PDA slants to get the pure culture of those individual species.

Isolation of Monosporous culture of $\boldsymbol{P}$. flabellatus, $P$. sajor-caju and $\boldsymbol{P}$. djamor (oyster pink)

Isolation of monosporous culture is one of the most important steps to develop homokaryons before aiming hybridization for strain improvement. Various techniques such as spore prints, serial dilution method was followed to get the monosporous cultures of those three species.

\section{Spore print method}

This method (Petersen and Ridly, 1996) was followed for single spore isolation of $P$. fabellatus, $P$. sajor-caju and $P$. djamor (oyster pink) [Plate $1 \& 2$ ].

\section{Serial dilution method}

The dilution method demonstrated by Bahukandi and Sharma (2002) from prepared spore suspension by taking spore from the spore print and suspended in sterile distilled water. Another way that the fresh mushroom cap from $P$. flabellatus, $P$. sajor-caju and $P$. djamor (oyster pink) were cut and dipped in sterilized water in petri plate by putting gills 
at downward position for hours (Plate 3). From this suspension further dilution up to $10^{-}$ ${ }^{4}$ was made, where the spore concentration was as low as up to 4 to 5 spores when seen under low power microscope (10X). Therefore, from the selected suspension a sterilized loop was dipped and streaked in PDA. After incubation for 3 to 4 days, single colony was isolated in PDA slants.

Growth performance of homokaryotic mycelium of $\boldsymbol{P}$. flabellatus, $\boldsymbol{P}$. sajor-caju and $P$. djamor (oyster pink) in Malt extract agar

To find out the best suitable and fastest growth of homokaryotic isolates of those three species, monosporous cultures were evaluated in $90 \mathrm{~mm}$ sterilized petri plates containing $15 \mathrm{ml}$ of malt extract agar (MEA) media where they were inoculated aseptically with mycelial disc of $5 \mathrm{~mm}$ size taken from the margins of actively growing single spore isolates and incubated at $25^{\circ} \mathrm{C}$ [Plate 8]. Malt extract agar was chosen because earlier worker like Stanley and Nyenke (2011) reported that highest mycelial growth rate of oyster mushroom (Pleurotus pulmonarius) was found in malt extract agar media. This media (MEA) was also used by Baral et al., (2018) while intraspecific hybridization between two Pleurotus flabellatus was done in the laboratory condition. Each isolate was replicated three times. Data pertaining to radial growth of the mycelium were recorded daily after completion of $45 \mathrm{~mm}$ growth in petri plates. Isolates of three species origin showing higher growth rate was selected for the hybridization.

\section{Inter specific hybridization}

Inter specific hybridization was done in petri plates using malt extract agar media. Isolates having higher growth potential was first inoculated separately in petri plates containing malt extract agar media. Crossing between three homokaryotic isolates of $P$. flabellatus, $P$. sajor-caju and oyster pink ( $P$. djamor) [Table 1, $2 \&$ 3] was performed by taking mycelial disc of $3 \mathrm{~mm}$ diameter of periphery of 7 days old homokaryotic cultures and placed in two opposite sides of the petri plates containing malt extract agar media [Plate $9 \& 10]$. Thereafter it was incubated for 3 to 4 days at $25^{\circ} \mathrm{C}$. After contact of two colonies a small amount of inoculum was taken by chopping from the meeting points of two different isolates and dikaryotization was further confirmed by the presence of clamp connections or by hyphal bridge [Plate $4 \&$ 11]. The inoculum showing dikaryotization was transferred to PDA slants for further use. In this way the inoculum from different meeting points were taken. 20 interspecific hybrids between $\mathrm{PF} \times \mathrm{PSC}$ and $\mathrm{OP} \times \mathrm{PSC}$ whereas 15 hybrids between $\mathrm{PF} \times \mathrm{OP}$ were picked up from the meeting points. These hybrids were then cultured for three generations to see whether there is any segregation of characters or not. The third generation hybrids were taken for further testing.

In vitro selection of potential inter specific strains of $\boldsymbol{P}$. flabellatus, $\boldsymbol{P}$. sajor-caju and $\boldsymbol{P}$. djamor (oyster pink)

To screen out the fastest growing hybrid crosses the growth test was carried out in the $90 \mathrm{~mm}$ petri plates containing $15 \mathrm{ml}$ of malt extract agar media. Hybrid stains of comprising of 20 inter species of oyster pink (P. djamor) and $P$. sajor-caju, 20 inter species of $P$. flabellatus and $P$. sajor-caju and 15 inter species of oyster pink and $P$. flabellatus was inoculated aseptically by $5 \mathrm{~mm}$ cork borer in a petri plates having malt extract agar media and growth performance was recorded separately [Plate 12, 13 \& 14]. Further selection was made on the basis of growth performance and the potential of spawn 
production in the rice and wheat grain. Twenty inter species was selected for further studies.

\section{Results and Discussion}

Selection of homokaryotic strains of $P$. flabellatus, $P$. sajor-caju and oyster pink ( $P$. djamor)

Isolation of monosporous culture is the $1^{\text {st }}$ step of hybridization in mushroom. 18 monosporous strains of $P$. flabellatus designated as PF1M to PF18M and 6 strains of $P$. sajor-caju designated as PSC1M to PSC6M and 5 strains of oyster pink ( $P$. djamor) designated as OP1M to OP5M were isolated following the method [Plate 5, $6 \&$ 7]. The strains were grown on malt extract agar (MEA) media considered as homokaryons which were evaluated for the variation in their growth rate in MEA media.

The highest mycelial growth of $32.50 \mathrm{~mm}$, $48.50 \mathrm{~mm}$ and $73 \mathrm{~mm}$ was recorded by PSC $3 M$ at $5^{\text {th }}, 7^{\text {th }}$ and $9^{\text {th }}$ day after inoculation, respectively in malt extract agar (MEA) media. The second highest growth of $28.50 \mathrm{~mm}, 44 \mathrm{~mm}$ and $68 \mathrm{~mm}$ was achieved in PSC5M at $5^{\text {th }}, 7^{\text {th }}$ and $9^{\text {th }}$ day after inoculation, respectively. The mycelial growth rate between $5^{\text {th }}$ to $7^{\text {th }}$ day of inoculation on MEA were highest in PSC3M $(16.00 \mathrm{~mm} /$ day $)$ followed by PSC2M (15.50 $\mathrm{mm}$ /day) and PSC5M (15.50 mm/day), least growth rate was found in PSC4M (13 $\mathrm{mm} /$ day). Growth rate between $7^{\text {th }}$ to $9^{\text {th }}$ day of inoculation was highest in PSC3M (24.50 $\mathrm{mm} /$ day) followed by PSC5M ( $24 \mathrm{~mm} /$ day) and least was in PSC2M (12.50 mm/day). So, the results showed that the maximum average mycelial growth rate between $5^{\text {th }}$ and $9^{\text {th }}$ day of inoculation was found in PSC3M (20.25 $\mathrm{mm} /$ day) which is closely followed by PSC5M (19.75 mm/day). So, by comparing overall growth performance of the homokaryons of $P$. sajor-caju, two highest growing strains namely PSC3M, PSC5M were selected as parents to be used in interspecific hybridization (Fig 1).

Regarding the growth performance of homokaryons of $P$. flabellatus, it was observed that at $9^{\text {th }}$ day after inoculation, the highest mycelial growth of $81 \mathrm{~mm}$ was recorded by $\mathrm{PF} 14 \mathrm{M}$ in malt extract agar (MEA) media which is followed by PF8M $(76.5 \mathrm{~mm})$. The third highest growth of 75 mm was found in PF11M, PF13M, PF16M and PF17M.

Between $5^{\text {th }}$ to $7^{\text {th }}$ day of inoculation on MEA, the growth rate ranged between $7.5 \mathrm{~mm} /$ day to $20.50 \mathrm{~mm} /$ day, where $P F 17 \mathrm{M}$ showed highest growth rate $(20.50 \mathrm{~mm} /$ day $)$ followed by PF16M (20.00 mm/day), PF8M (19.5 $\mathrm{mm} /$ day) and PF11M (18.5 mm/day) and slowest growth was found in PF3M (7.5 $\mathrm{mm} /$ day). When growth rate between $7^{\text {th }}$ to $9^{\text {th }}$ day was studied, the rate ranged from 6.5 $\mathrm{mm}$ /day to $26.00 \mathrm{~mm} /$ day, where maximum growth rate was found in PF14M (26.00 $\mathrm{mm} /$ day) followed by PF11M (25.00 $\mathrm{mm} /$ day). If we look into the overall growth rate between $5^{\text {th }}$ to $9^{\text {th }}$ day after inoculation, the mean mycelial growth rate was found in PF8M (20.25 mm/day) followed by PF11M (21.50 mm/day), PF16M (20.50 mm/day), PF17M (21.50 mm/day) and PF14M (21 $\mathrm{mm} /$ day). From the overall growth performance of the homokaryons of $P$. flabellatus, four strains namely PF8M, PF11M, PF16M and PF17M from the above experiment were selected as parents to be used in interspecific hybridization (Fig 2).

In malt extract agar media, the highest mycelial growth of $38.50 \mathrm{~mm}, 54 \mathrm{~mm}$ and 74 $\mathrm{mm}$ was recorded by OP5M at $5^{\text {th }}, 7^{\text {th }}$ and $9^{\text {th }}$ day after inoculation, respectively. The second highest growth of $27.50 \mathrm{~mm}$ and 57 $\mathrm{mm}$ was found in OP3M at $5^{\text {th }}$ and $9^{\text {th }}$ day 
after inoculation, respectively whereas the second highest growth of $41 \mathrm{~mm}$ was achieved by OP1M at $7^{\text {th }}$ day after inoculation. In case of oyster pink, between $5^{\text {th }}$ to $7^{\text {th }}$ day of inoculation on MEA the growth rate ranged between $5.00 \mathrm{~mm} /$ day to $16.00 \mathrm{~mm} /$ day, where maximum growth rate was showed by OP1M (16.00 $\mathrm{mm} /$ day $)$ followed by OP5M (15.50 mm/day). Slowest growth rate was observed in OP2M (5.00 $\mathrm{mm} /$ day). Between $7^{\text {th }}$ to $9^{\text {th }}$ day of inoculation maximum growth was found in OP5M (20.00 mm/day) followed by OP3M (17.00 mm/day) and OP1M (14.50 mm/day). Slowest rate was recorded in OP4M (6.00 $\mathrm{mm} /$ day). Overall, from $5^{\text {th }}$ to $9^{\text {th }}$ day of inoculation the mean mycelial highest growth rate was observed in OP5M (17.75 mm/day) followed by OP1M (15.25 mm/day). So from the above experiment OP1M and OP5M was selected as a parents to be used in the interspecific hybridization (Fig 3).

\section{Medium for hybridization}

It was clear from the above results that MEA were best suited media for monokaryotic strains of $P$. flabellatus $P$. sajor-caju and $P$. djamar. The average growth rate of both species of Pleurotus on MEA was found to be the best medium for interspecific hybridization between selected monokaryotic strains of $P$. flabellatus and $P$. sajor-caju and $P$. djamor. Hernandez and Salmones (2008) had obtained 16 strains of $P$. ostreatus by interbreeding in which selection was done on the radial growth rate of monokaryotic mycelia. He found that the biological efficiency of mushroom depends on the development of mycelia in the first cultural stage. Mycelium growth of Pleurotus depends on several factors such as growing media, different media concentration, $\mathrm{pH}$, temperature, nutrient element and some environmental factors (Ahmed et. al., 2013). Malt extract agar media as one of the suitable cultural media for the growth of edible fungus was reported by Kalm and Kalyoncu (2008).

In vitro Evaluation of Interspecific Hybrids of $P$. flabellatus and $P$. sajor-caju and $P$. djamor (Oyster pink)

Twenty inter specific hybrids of $P$. flabellatus and $P$. sajor-caju were tested for their growth on MEA under in vitro condition Significant variations in growth rate on 6 th day to $8^{\text {th }}$ day after inoculation among the hybrids were observed. Highest mycelial growth of 70.50 mm was recorded by PF $\times$ PSC 6 at $6^{\text {th }}$ day after inoculation whereas $2^{\text {nd }}$ and $3^{\text {rd }}$ highest growth of $67.50 \mathrm{~mm}$ and $64 \mathrm{~mm}$ was recorded by $\mathrm{PF} \times \mathrm{PSC} 10$ and $\mathrm{PF} \times \mathrm{PSC} 7$, respectively. Moderately growing hybrids were recorded in $\mathrm{PF} \times \mathrm{PSC} 3, \mathrm{PF} \times \mathrm{PSC} 7, \mathrm{PF} \times \mathrm{PSC} 4, \mathrm{PF} \times$ PSC1, PF $\times$ PSC20, $\mathrm{PF} \times \mathrm{PSC} 2 \quad(12.50$ $\mathrm{mm} /$ day, $13.00 \mathrm{~mm} /$ day, $13.50 \mathrm{~mm} /$ day, 14.50 $\mathrm{mm} /$ day, $15.00 \mathrm{~mm} /$ day, $16.50 \mathrm{~mm} /$ day, respectively). Slowest growing hybrid was PF $\times$ PSC10 (10.50 mm/day) (Fig 4).

Significant variation in growth rate from $6^{\text {th }}$ to $8^{\text {th }}$ day after inoculation within the hybrids of oyster pink and P. sajor-caju was observed. Highest growth rate was observed in OP $\times$ PSC $5 \quad(21.50 \mathrm{~mm} /$ day $)$ which was significantly at par with the growth rate of $\mathrm{OP} \times \mathrm{PSC} 4(21.00 \mathrm{~mm} /$ day $), \mathrm{OP} \times \mathrm{PSC} 8$ $(20.50 \mathrm{~mm} /$ day $)$, OP $\times$ PSC $15 \quad(20.00$ $\mathrm{mm} /$ day) (Fig 5). Moderately high growth rate was observed in OP $\times$ PSC1, OP $\times$ PSC9, OP $\times$ PSC14, OP $\times$ PSC13 and OP $\times$ PSC16 (15.00 mm/day, $17.00 \mathrm{~mm} /$ day, 15.50 $\mathrm{mm} /$ day, $18.00 \mathrm{~mm} /$ day and $16.00 \mathrm{~mm} /$ day, respectively). Lowest growth rate was found in $\mathrm{OP} \times \mathrm{PSC} 11$ and $\mathrm{OP} \times \mathrm{PSC} 17(10.50$ $\mathrm{mm} /$ day).

The Interspecific hybrids of Oyster pink and $P$. flabellatus then evaluated to screen for identifying the strains with higher growth potential Highest growth at $8^{\text {th }}$ day after 
inoculation was occurred by OP $\times$ PF9 $(80$ $\mathrm{mm}) .2^{\text {nd }}$ and $3^{\text {rd }}$ highest growth of $79.50 \mathrm{~mm}$ and $78 \mathrm{~mm}$ was observed in OP $\times$ PF15 and OP $\times$ PF10, respectively. In respect of growth rate, it was highest in OP $\times$ PF5 followed by $\mathrm{OP} \times \mathrm{PF} 1, \mathrm{OP} \times \mathrm{PF} 9, \mathrm{OP} \times \mathrm{PF} 11, \mathrm{OP} \times \mathrm{PF} 4$, OP $\times$ PF15 $(21.50 \mathrm{~mm} /$ day, $20.0 \mathrm{~mm} /$ day, $19.50 \mathrm{~mm} /$ day, $18.50 \mathrm{~mm} /$ day, $18.50 \mathrm{~mm} /$ day, $17.00 \mathrm{~mm} /$ day, respectively) (Fig 6). Moderately growing hybrids were found to be $\mathrm{OP} \times \mathrm{PF} 3(16.00 \mathrm{~mm} /$ day $)$ followed by $\mathrm{OP} \times$ PF13 (12.50 mm/day), OP $\times$ PF14 (11.50 $\mathrm{mm}$ /day). Slower growing hybrids were OP $\times$ PF12 $(7.00 \mathrm{~mm} /$ day $)$ and OP $\times$ PF8 $(8.50$ $\mathrm{mm} /$ day) Fast growing hybrids were taken under consideration to determine their qualitative and quantitative performance during cultivation.

In conclusion, variations in growth rate were observed in monokaryotic isolates in MEA medium was selected as parent strains for dikaryotization of $P$. flabellatus and $P$. sajorcaju and P. djamor (Oyster pink). Dikaryotic mycelium showed the highest growth rate of above as compared to monokaryotic isolates of P. flabellatus and P. sajor-caju and $P$. djamor (Oyster pink).

Table.1 Parentage and interspecific hybrids of Pleurotus

\begin{tabular}{|l|l|}
\hline Parentage & Hybrids \\
\hline $\mathrm{PF} 8 \mathrm{M} \times \mathrm{PSC} 3 \mathrm{M}$ & $\mathrm{PF} \times \mathrm{PSC} 1, \mathrm{PF} \times \mathrm{PSC} 2, \mathrm{PF} \times \mathrm{PSC} 3, \mathrm{PF} \times \mathrm{PSC} 4$ \\
\hline $\mathrm{PF} 8 \mathrm{M} \times \mathrm{PSC} 5 \mathrm{M}$ & $\mathrm{PF} \times \mathrm{PSC} 5, \mathrm{PF} \times \mathrm{PSC} 6$ \\
\hline $\mathrm{PF} 11 \mathrm{M} \times \mathrm{PSC} 3 \mathrm{M}$ & $\mathrm{PF} \times \mathrm{PSC} 7, \mathrm{PF} \times \mathrm{PSC} 8, \mathrm{PF} \times \mathrm{PSC} 9$ \\
\hline $\mathrm{PF} 11 \mathrm{M} \times \mathrm{PSC} 5 \mathrm{M}$ & $\mathrm{PF} \times \mathrm{PSC} 10, \mathrm{PF} \times \mathrm{PSC} 11$ \\
\hline $\mathrm{PF} 16 \mathrm{M} \times \mathrm{PSC} 3 \mathrm{M}$ & $\mathrm{PF} \times \mathrm{PSC} 12, \mathrm{PF} \times \mathrm{PSC} 13, \mathrm{PF} \times \mathrm{PSC} 14$ \\
\hline $\mathrm{PF} 16 \mathrm{M} \times \mathrm{PSC} 5 \mathrm{M}$ & $\mathrm{PF} \times \mathrm{PSC} 15, \mathrm{PF} \times \mathrm{PSC} 16$ \\
\hline $\mathrm{PF} 17 \mathrm{M} \times \mathrm{PSC} 3 \mathrm{M}$ & $\mathrm{PF} \times \mathrm{PSC} 17, \mathrm{PF} \times \mathrm{PSC} 18$ \\
\hline $\mathrm{PF} 17 \mathrm{M} \times \mathrm{PSC} 5 \mathrm{M}$ & $\mathrm{PF} \times \mathrm{PSC} 19, \mathrm{PF} \times \mathrm{PSC} 20$ \\
\hline
\end{tabular}

PF: Pleurotus flabellatus; PSC: P. sajor-caju

Table.2 Parentage and interspecific hybrids

\begin{tabular}{|l|l|}
\hline Parentage & Hybrids \\
\hline PSC3M $\times$ OP1M & $\begin{array}{l}\text { OP } \times \text { PSC1, OP } \times \text { PSC2, OP } \times \text { PSC3, OP } \times \text { PSC4, OP } \times \text { PSC5, OP } \times \\
\text { PSC6 }\end{array}$ \\
\hline PSC3M $\times$ OP5M & OP $\times$ PSC7, OP $\times$ PSC, OP $\times$ PSC 9, OP $\times$ PSC10, OP $\times$ PSC11 \\
\hline PSC5M $\times$ OP1M & OP $\times$ PSC12, OP $\times$ PSC13, OP $\times$ PSC14, OP $\times$ PSC15, OP $\times$ PSC16 \\
\hline PSC5M $\times$ OP5M & OP $\times$ PSC17, OP $\times$ PSC18, OP $\times$ PSC19, OP $\times$ PSC20 \\
\hline
\end{tabular}

PSC: P. sajor-caju; OP: Oyster pink 
Table.3 Parentage and interspecific hybrids

\begin{tabular}{|l|l|}
\hline Parentage & Hybrids \\
\hline $\mathrm{PF} 8 \mathrm{M} \times \mathrm{OP} 1 \mathrm{M}$ & $\mathrm{OP} \times \mathrm{PF} 1, \mathrm{OP} \times \mathrm{PF} 2, \mathrm{OP} \times \mathrm{PF} 3$ \\
\hline $\mathrm{PF} 8 \mathrm{M} \times \mathrm{OP} 5 \mathrm{M}$ & $\mathrm{OP} \times \mathrm{PF} 4, \mathrm{OP} \times \mathrm{PF} 5$ \\
\hline $\mathrm{PF} 11 \mathrm{M} \times \mathrm{OP} 1 \mathrm{M}$ & $\mathrm{OP} \times \mathrm{PF} 6$ \\
\hline $\mathrm{PF} 11 \mathrm{M} \times \mathrm{OP} 5 \mathrm{M}$ & $\mathrm{OP} \times \mathrm{PF} 7, \mathrm{OP} \times \mathrm{PF} 8$ \\
\hline $\mathrm{PF} 16 \mathrm{M} \times \mathrm{OP} 1 \mathrm{M}$ & $\mathrm{OP} \times \mathrm{PF}, \mathrm{OP} \times \mathrm{PF} 10$ \\
\hline $\mathrm{PF} 16 \mathrm{M} \times \mathrm{OP} 5 \mathrm{M}$ & $\mathrm{OP} \times \mathrm{PF} 11, \mathrm{OP} \times \mathrm{PF} 12$ \\
\hline $\mathrm{PF} 17 \mathrm{M} \times \mathrm{OP} 1 \mathrm{M}$ & $\mathrm{OP} \times \mathrm{PF} 13, \mathrm{OP} \times \mathrm{PF} 14$ \\
\hline $\mathrm{PF} 17 \mathrm{M} \times \mathrm{OP} 5 \mathrm{M}$ & $\mathrm{OP} \times \mathrm{PF} 15$ \\
\hline
\end{tabular}

PF: Pleurotus flabellatus; OP: Oyster pink

Plate.1 Discharging of spore from fruit body Plate.2 Spore print from fruit body

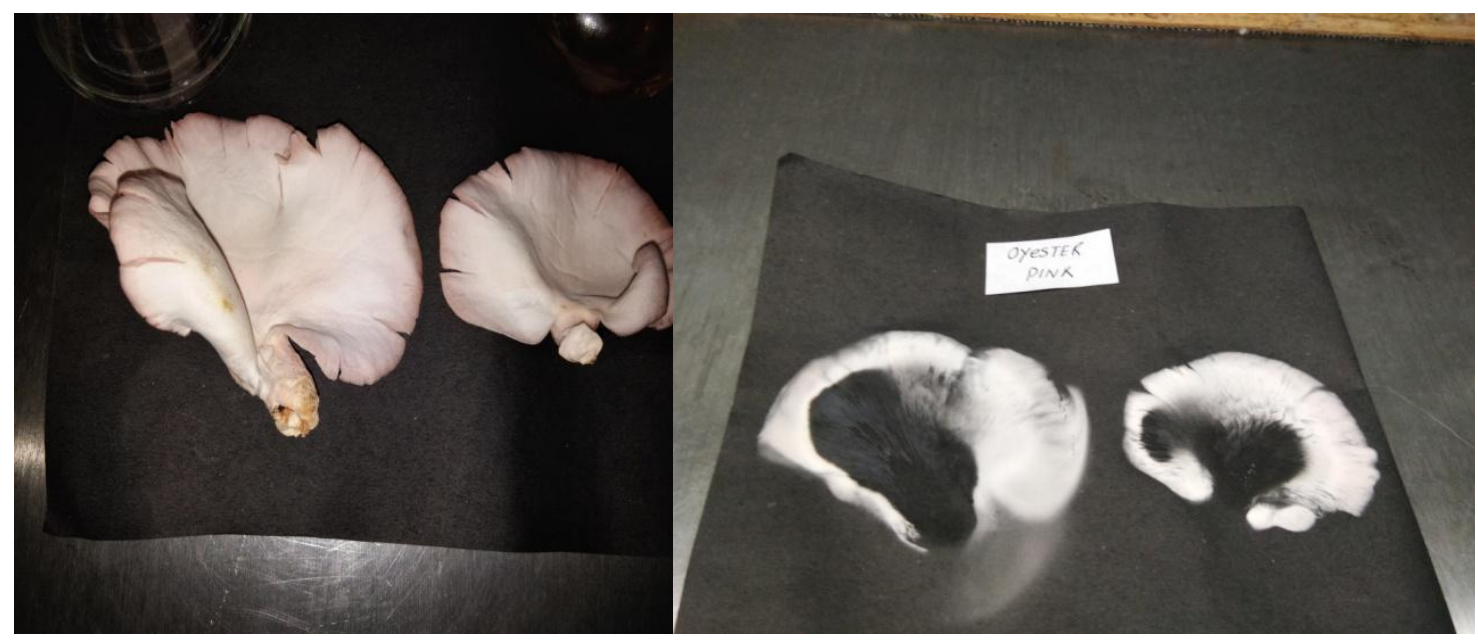

Fig.1 Growth rate of $P$. sajor caju monosporous culture in MEA media

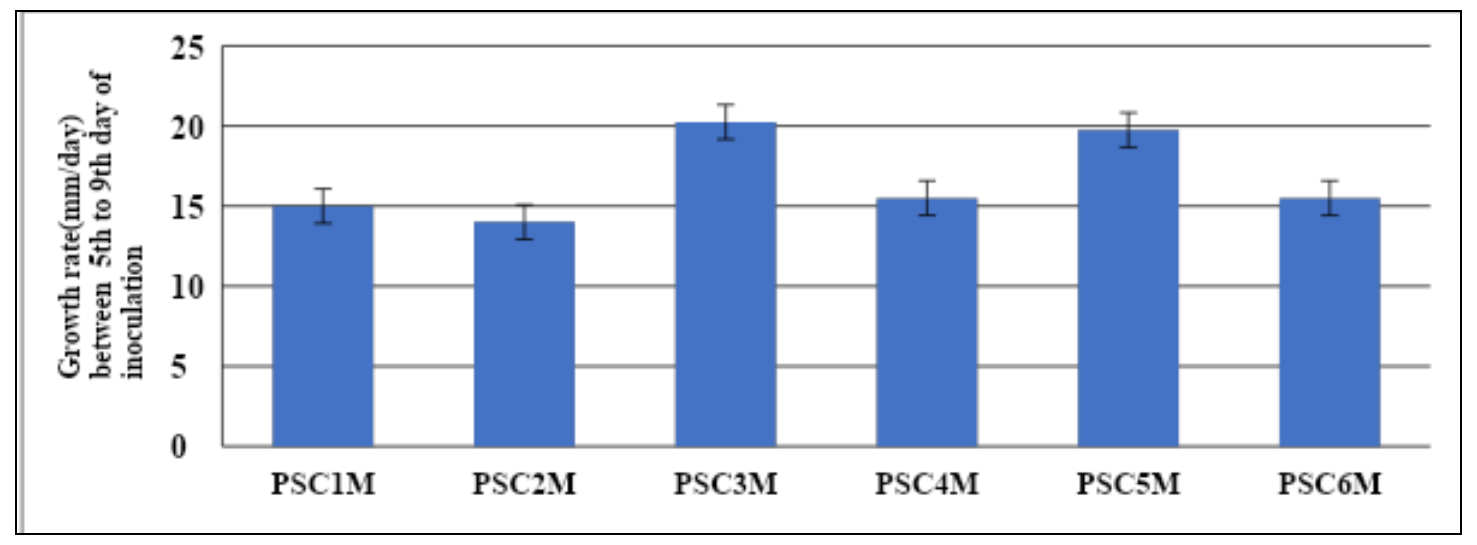


Fig.2 Growth rate of $P$. flabellatus monosporous culture in MEA media

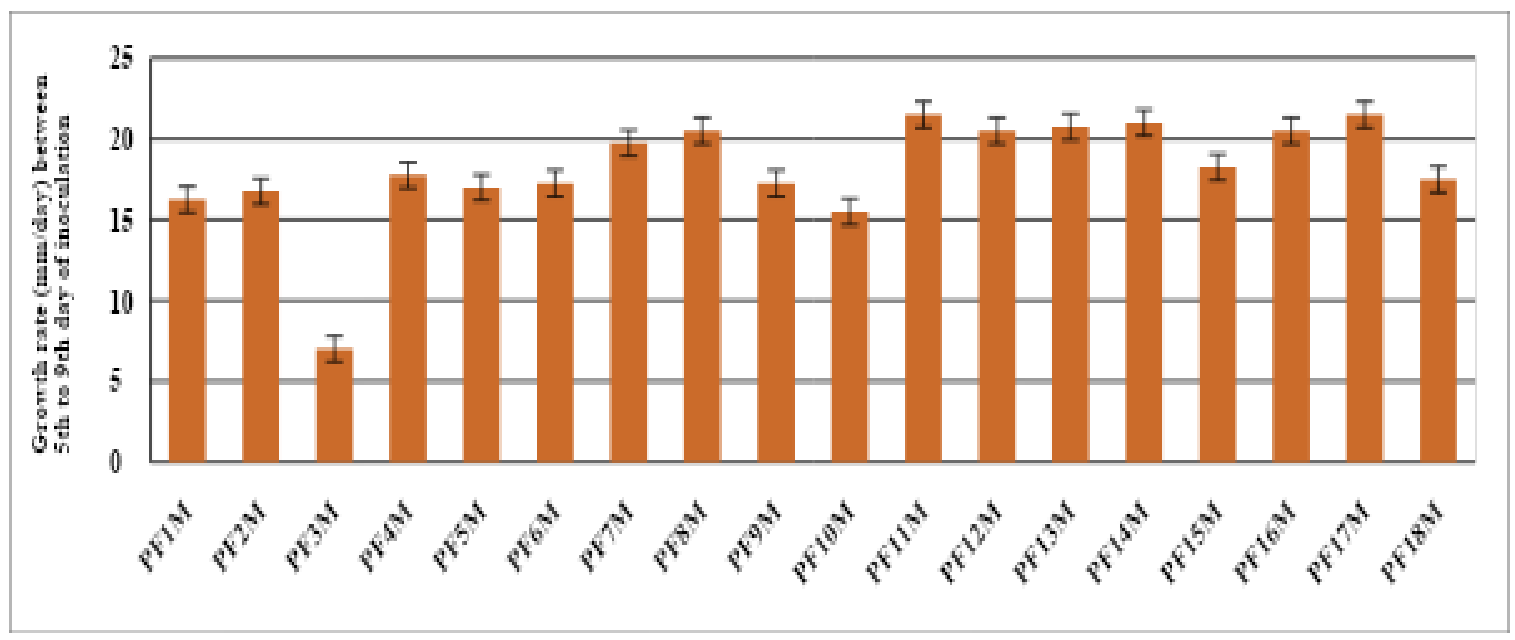

Fig.3 Growth rate of $P$. djamor (OP) monosporous culture in MEA media

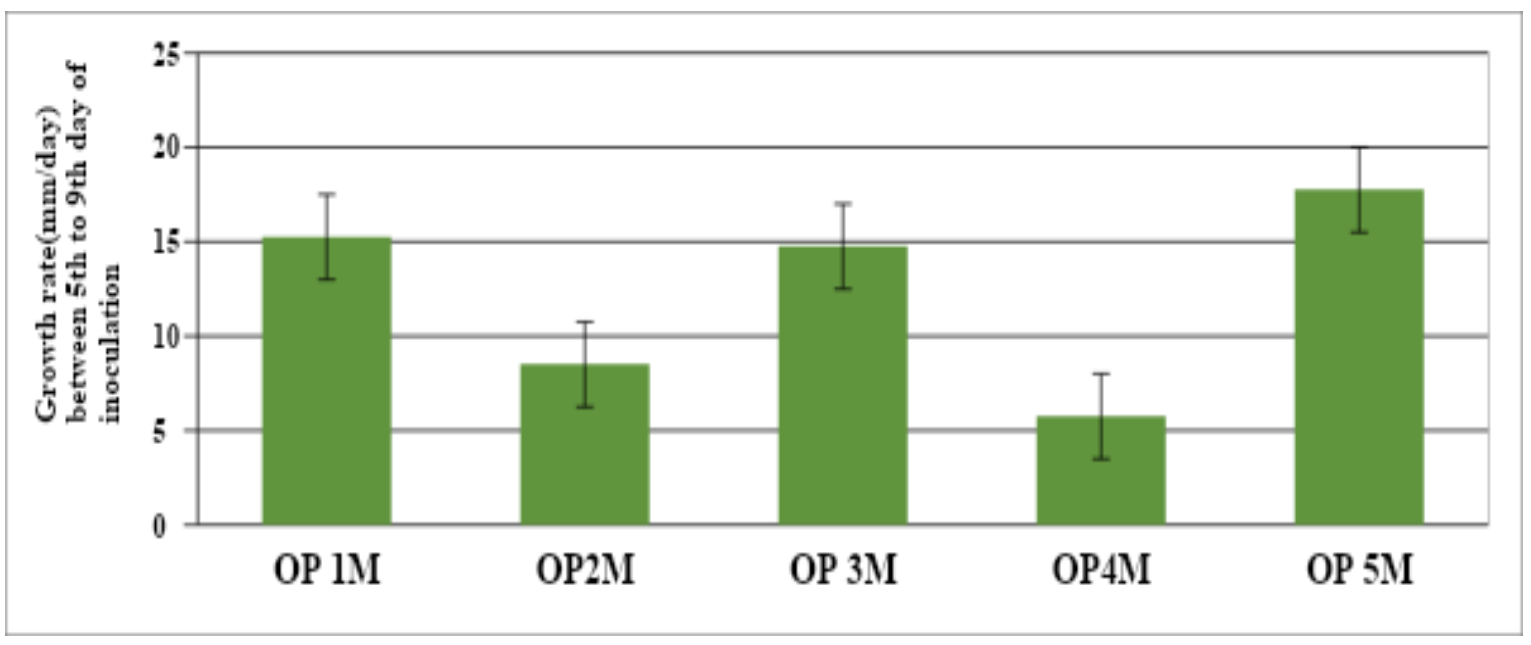

Fig.4 Growth rate of PF $\times$ PSC hybrids in MEA media

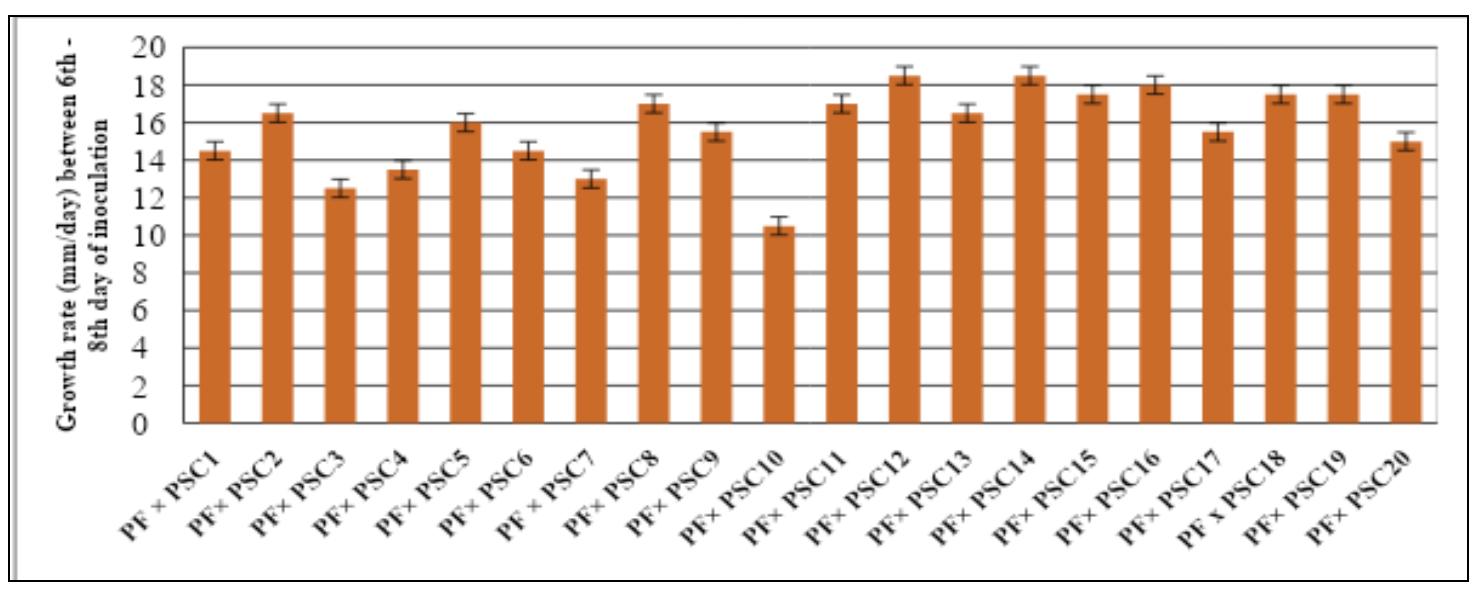


Fig.5 Growth rate of OP $\times$ PSC hybrids in MEA media

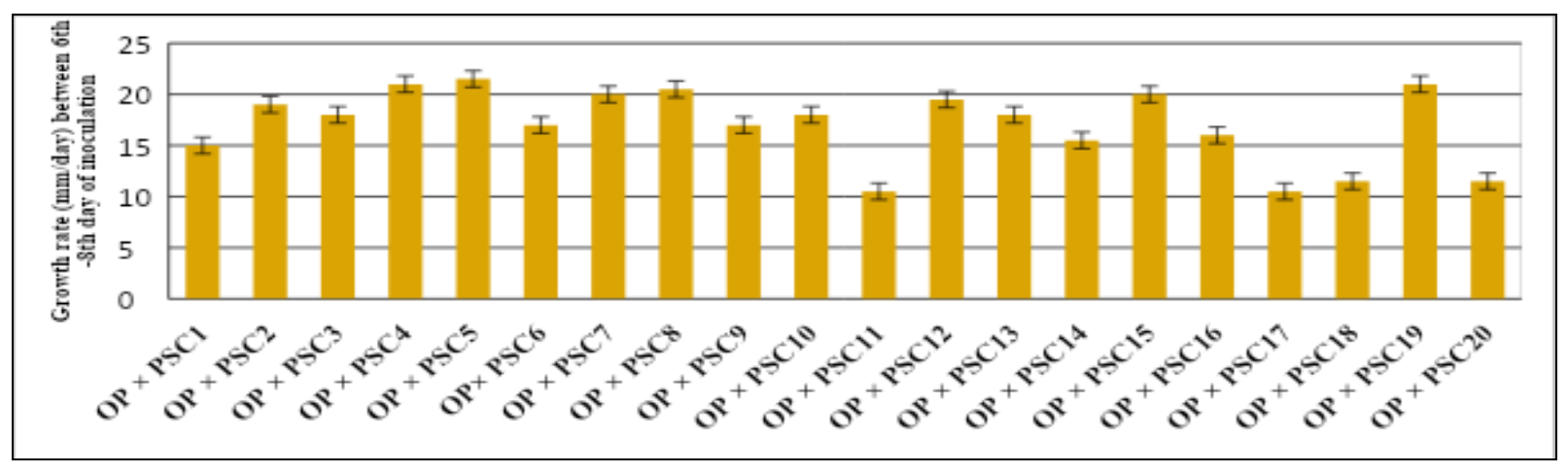

Fig.6 Growth rate of OP $\times$ PF hybrids in MEA media

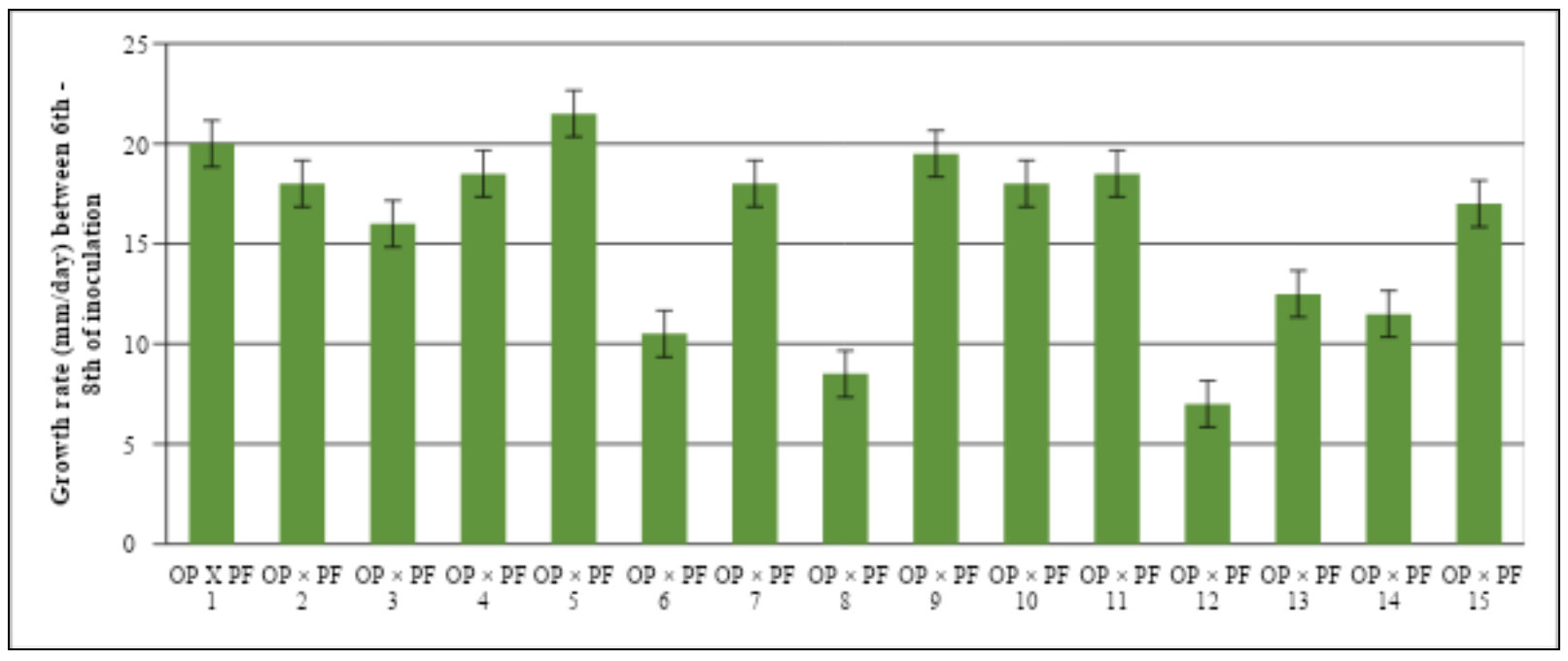

Plate.3 Isolation of spore through serial dilution Plate.4 Hyphal tip without clamp connection
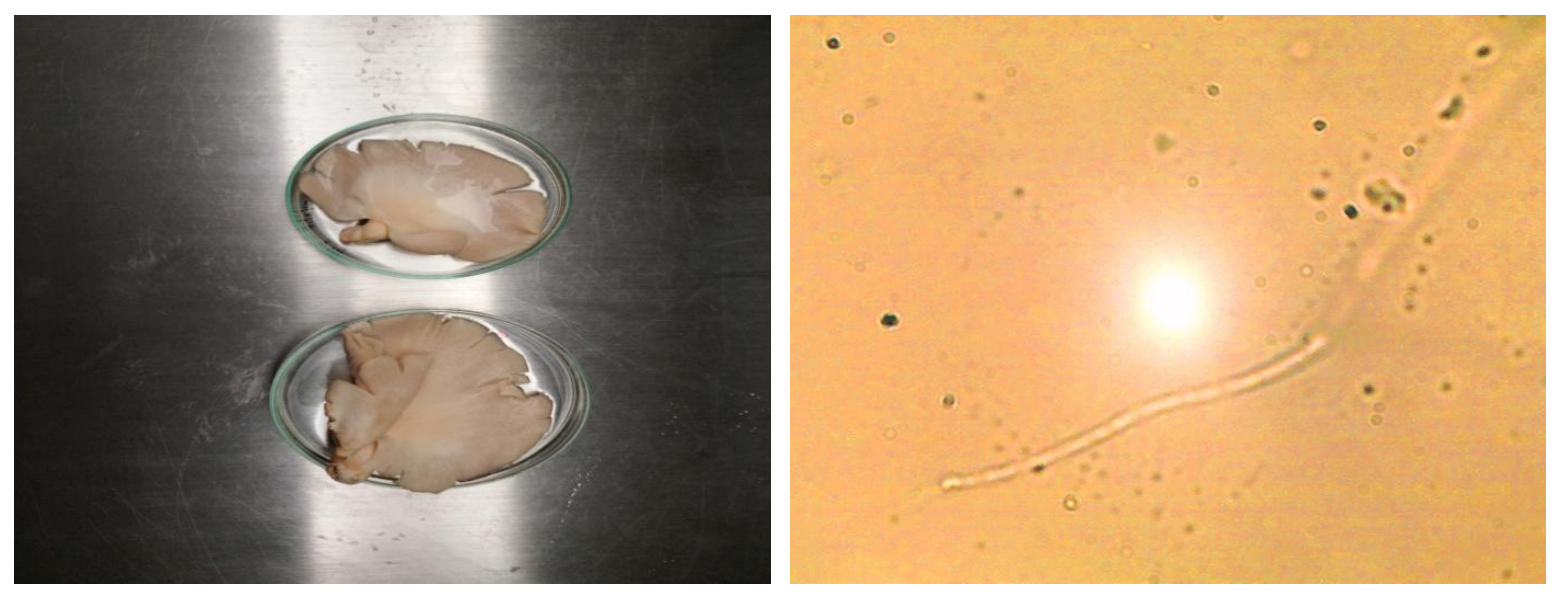
Plate.5 Monosporus culture of $P$. flabellatus Plate.6 Monosporus culture of P. sajor-caju
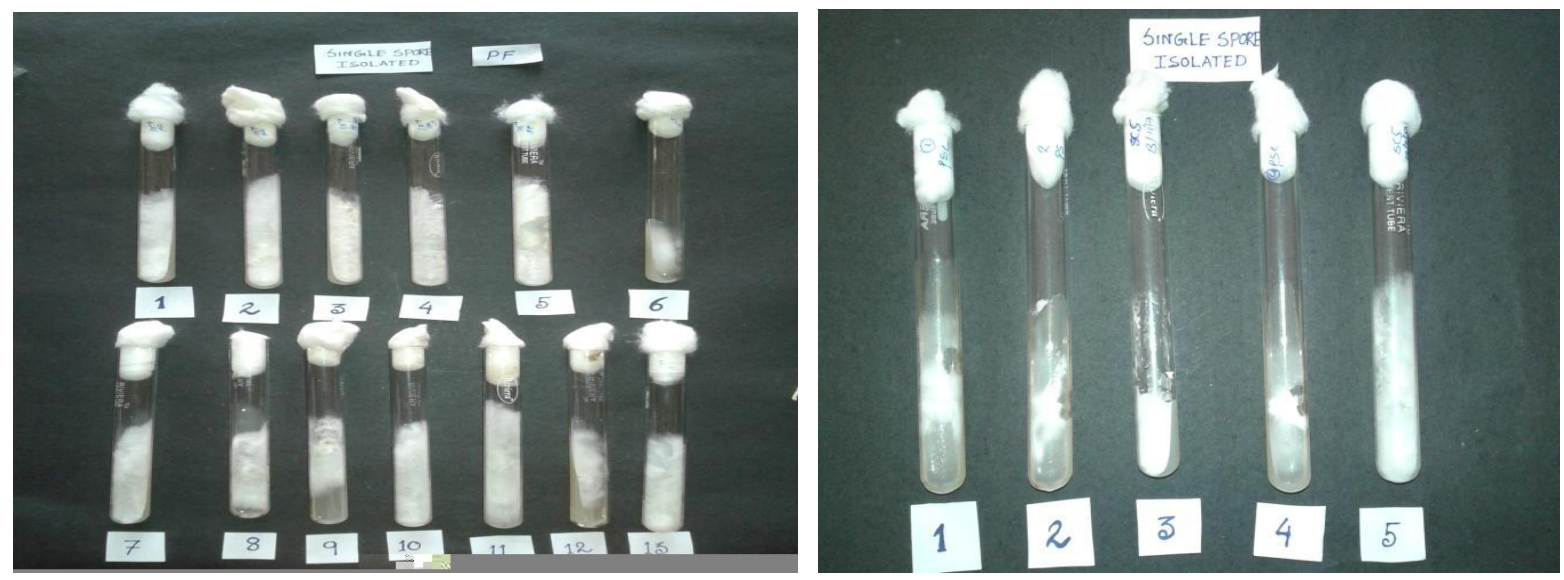

Plate.7 Monosporus culture of Oyster pink

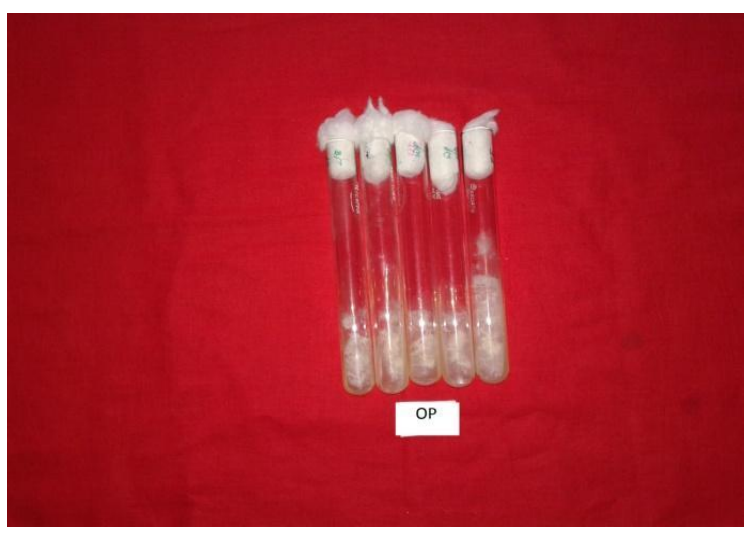

Plate.8 Variation in growth of homokaryons of Oyster pink and P. flabellatus in Malt extract agar media

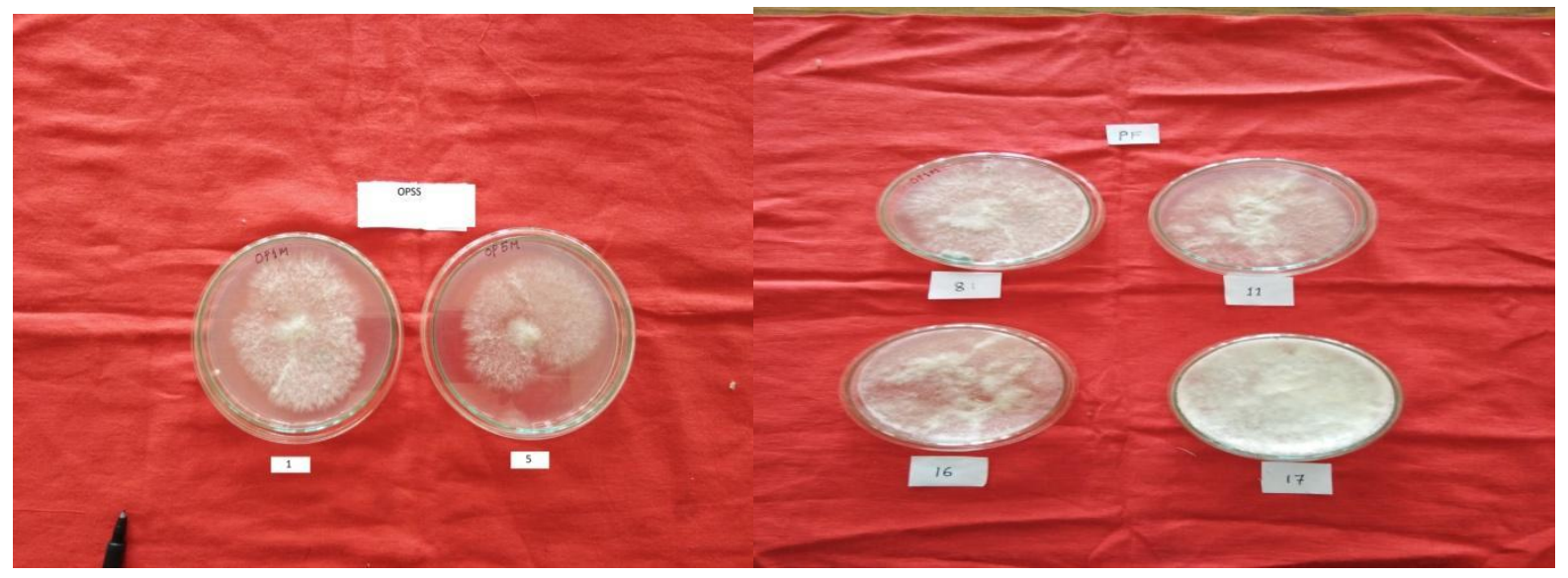


Plate.9 Somatic Hybridization of Pleurotus

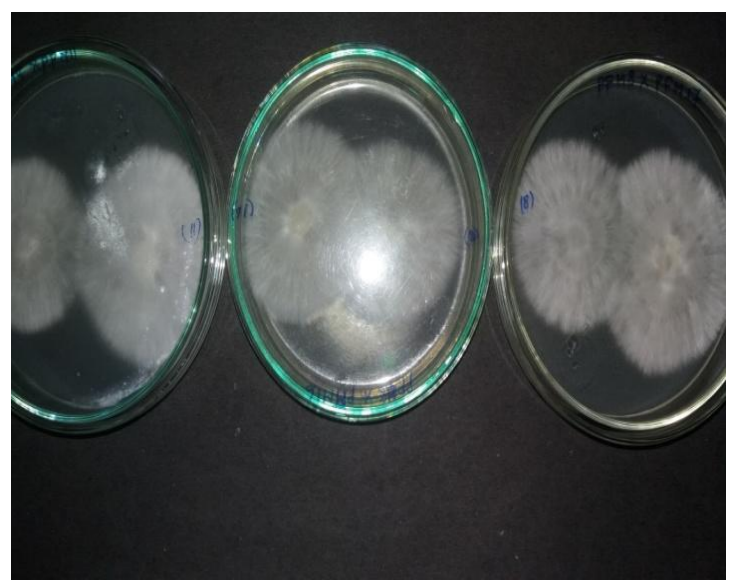

Plate.10 Isolation of hybrids from meeting points

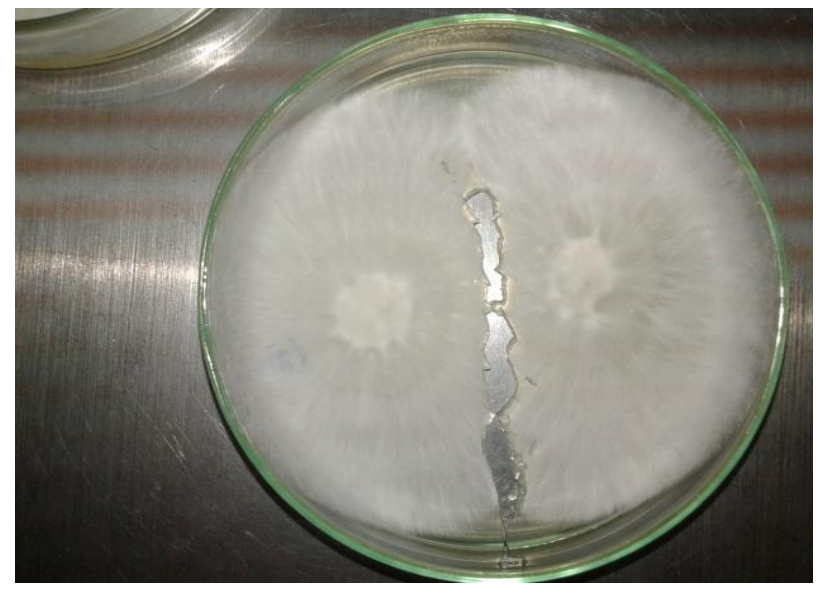

Plate.11 Microscopy for presence of clamp connection and hyphal bridge to ascertain hybridization

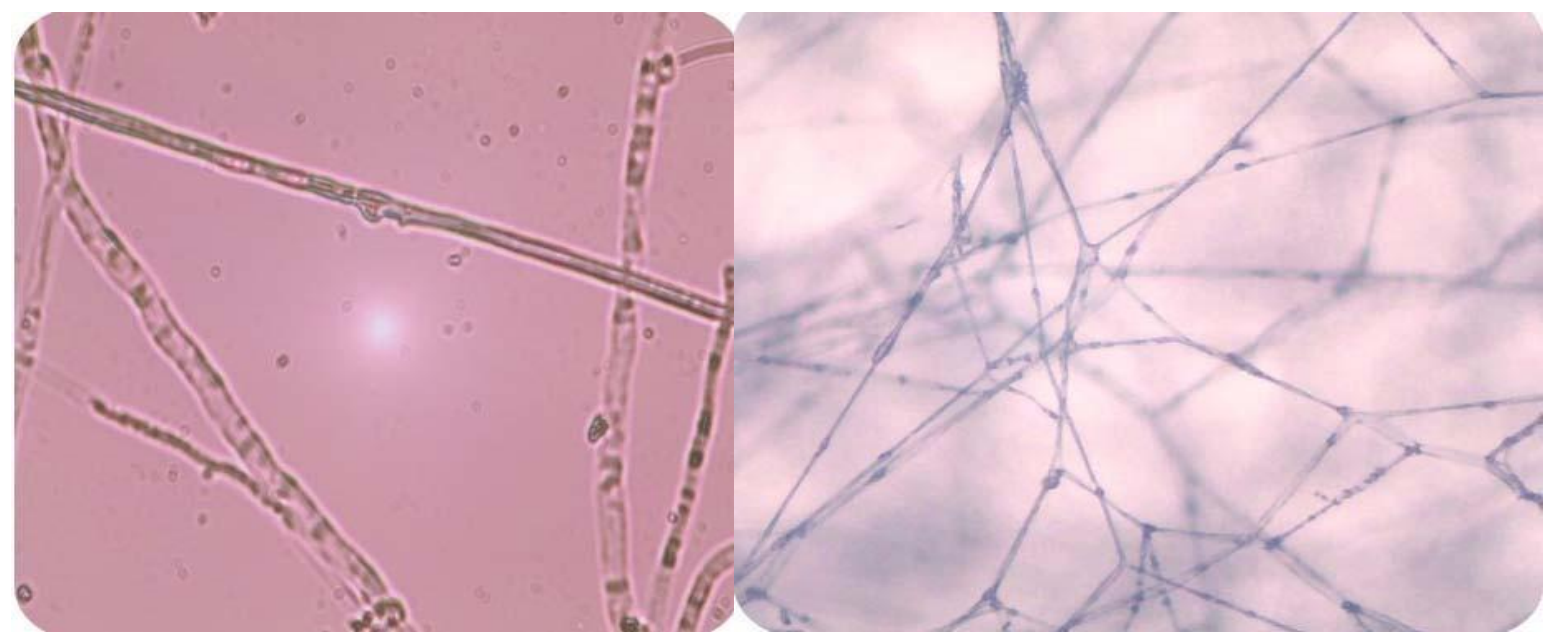

Plate.12 Growth test of interspecific hybrids between P. flabellatus and P. sajor-caju

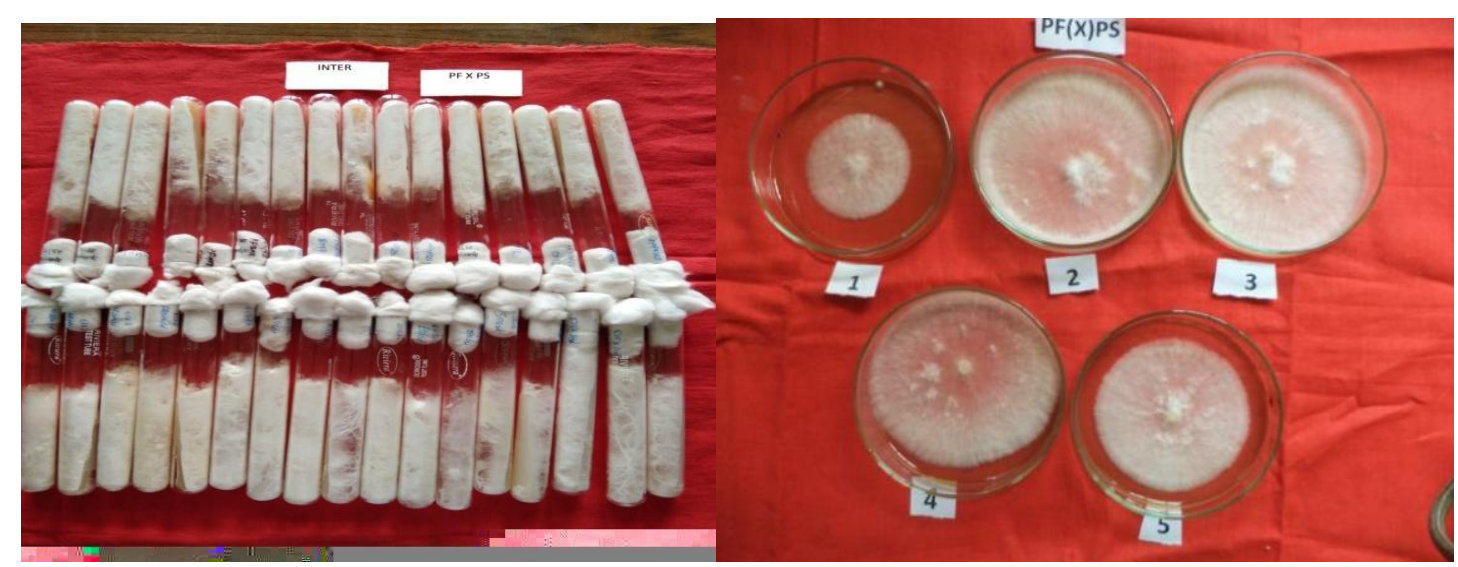


Plate.13 Growth test of interspecific hybrids between Oyster pink \& P. sajor-caju

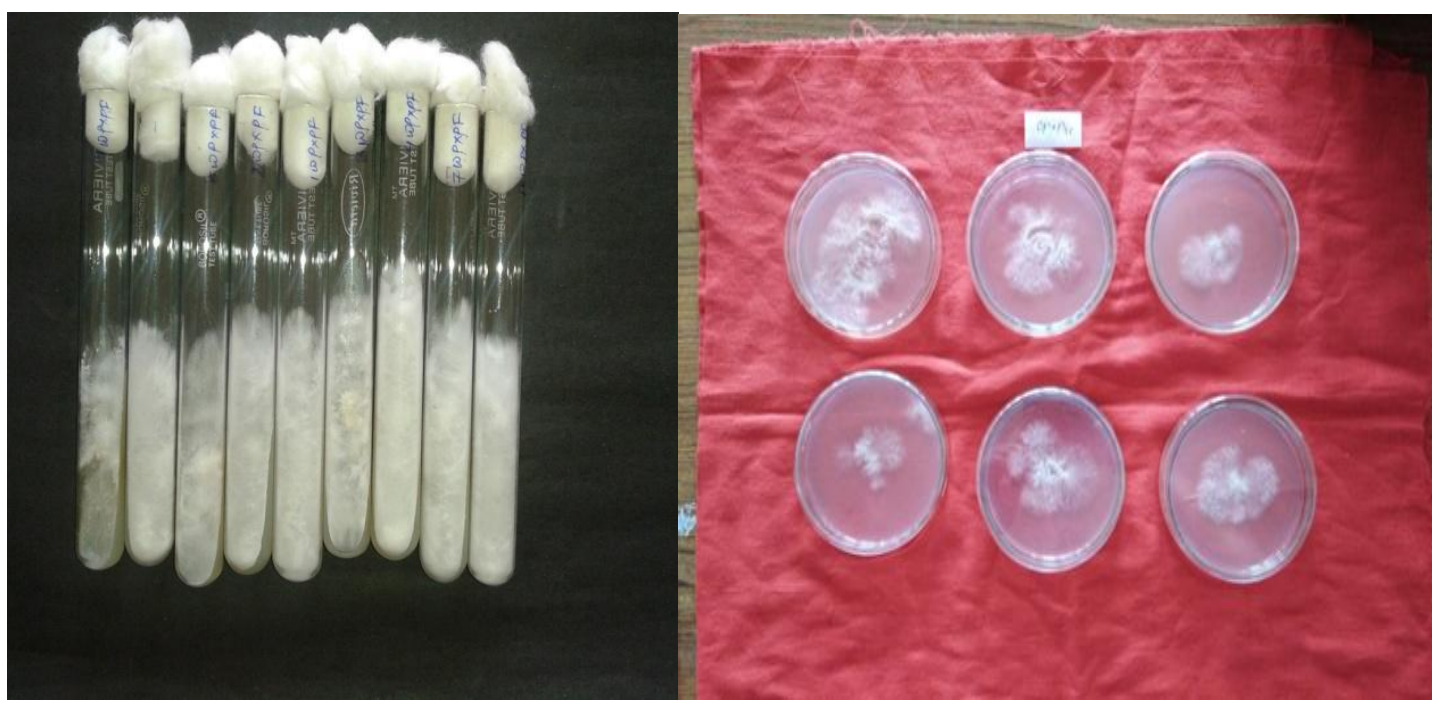

Plate.14 Growth test of interspecific hybrids between Oyster pink \& P. flabellatus

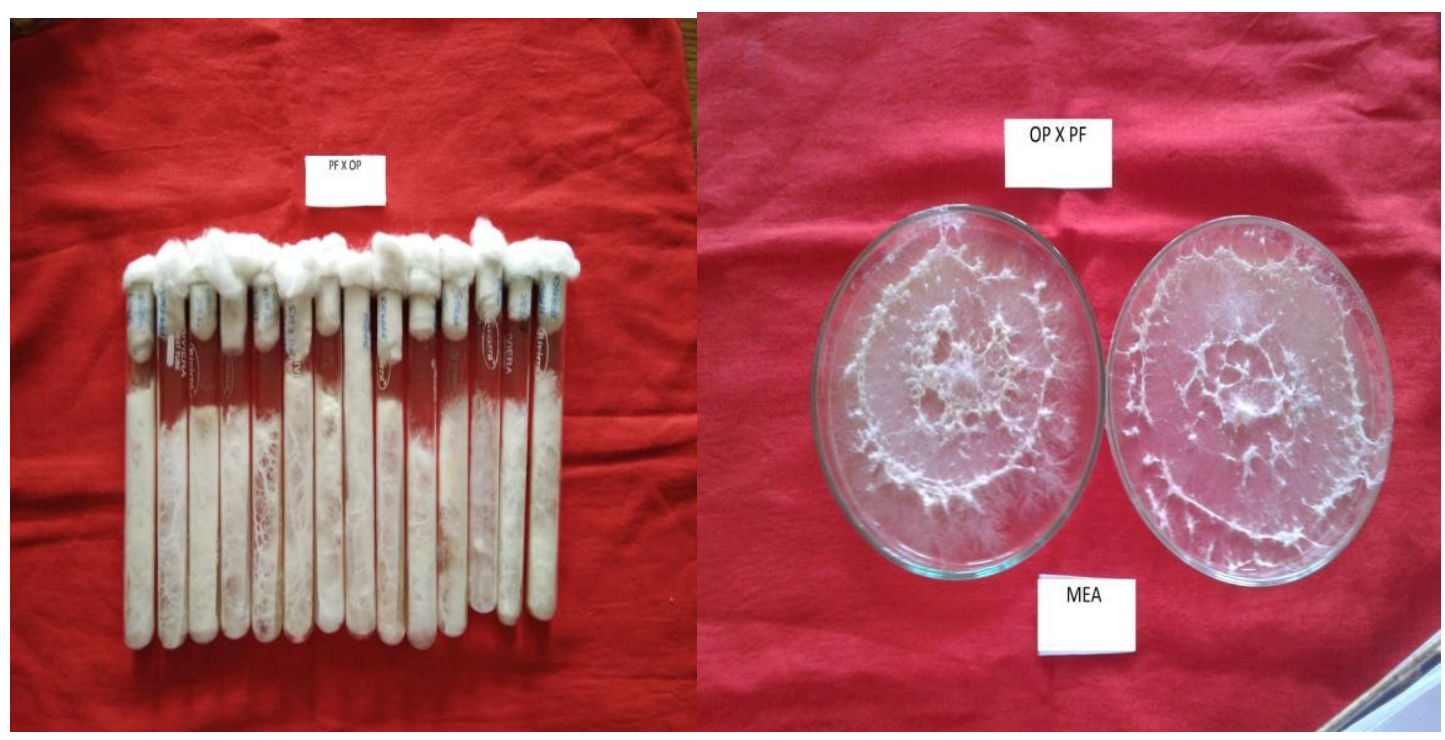

\section{References}

Ahmed M., Abdullah N., Ahmed K.U. and Bhuyan B. 2013. Yield and nutritional composition of oyster mushroom strains newly introduced in Bangladesh. Pesq. agropec. bras. Brasília. 48(2): 197-202, DOI: $10.1590 / \mathrm{S} 0100-$ 204X2013000200010.

Bahukhandi D. and Sharma R.K. 2002. Interspecific hybridization in Pleurotus species. Indian Phytopathology. (1):61-66.

Baral D., Roy A., Thapa S. and Chettri D. 2018. Selection of Culture Media and Monokaryotic isolates of Pleurotus flabellatus and $P$. sajor-caju for their Dikaryotization Followed by Performance Testing of Dikaryotic Isolates on Malt Extract Agar Medium. Current Journal of Applied Science and Technology. 26(5):1-10. DOI: 
10.9734/CJAST/2018/40423

Hernandez R.G. and Salmones D. 2008. Obtaining and characterizing Pleurotus ostreatus strains for commercial cultivation under warm environmental conditions. Scientia Horticulturae. 118:106-110.

Kalm E. and Kalyoncu F. 2008. Mycelial growth rate of some morels Morchella Spp. In four different microbiological media. American-Eurasian Journal of Agriculture and Environmental Science.
3:861-864.

Petersen R.H. and Ridley G.S. 1996. A New Zealand Pleurotus with MultipleSpecies Sexual Compatibility. Mycologia. 88(2): 198-207

Stanley H.O. and Nyenke C.U. 2011. Cultural studies on mycelia of Pleurotus pulmonarius (oyster mushroom) in selected culture media, International Journal of Sciences and Nature. 2(2): 183- 185.

\section{How to cite this article:}

Aparajita Dhar, K. Sinijadas, Pulak Bhaumik, Suman Datta and Sekhar Bandyopadhyay. 2020. Selection of Monokaryotic Isolates of Pleurotus sajor-caju, Pleurotus flabellatus and Pleurotus djamor for their Dikaryotization. Int.J.Curr.Microbiol.App.Sci. 9(12): 2072-2084.

doi: https://doi.org/10.20546/ijcmas.2020.912.244 